\title{
PENDIDIKAN MORAL DALAM NOVEL FONTENAY KE MAGALLIANES
}

\author{
Arju Susanto \\ Fakultas Bahasa dan Sastra \\ Universitas Nasional \\ Arjuna12susanto@gmail.com
}

\begin{abstract}
ABSTRAK
1970-an adalah merupakan tahun kejayaan sejumlah penulis perempuan sekaligus menjadi salah satu penyebab terbitnya novel serta berbagai majalah atau tabloid yang dikhususkan bagi wanita ataupun untuk masyarakat umum sehingga dibutuhkan lebih banyak bahan untuk mengisinya. Berkait dengan kenyataan tersebut, maka, penelitian novel yang berjudul Dari Fontenay ke Magallihanse karya Nh. Dini, adalah merupakan contoh salah satu novel yang bercerita tentang kejiwaan, moral, etika, dan humanisme yang layak untuk dicermati dan diteliti. Sebagaimana kita ketahui, konsep moral dan etika dalam perspektif filsafat dipahami sebagai sistem nilai yang berhubungan dengan baik dan buruk yang disepakati oleh masyarakat tertentu sepanjang sejarahnya. Manusia sebagai homo socius selalu terikat dengan tata nilai yang telah disepakati bersama. Oleh karena itu dimana ada masyarakat di sanalah ada hukum atau etika (ubi socius, ibi ius). Selanjutnya, lewat metode kualitatif dan mencermati nilai-nilainya khususnya hal-hal yang berkenaan dengan psikologi, moral dan etika, tokoh wanita, maka, tampak dengan jelas betapa dari analisis data dan informasi dapat diketahui bahwa dari jumlah 22 temuan/ adegan cerita (scene) yang menunjukkan adegan nilai-nilai/ kejiwaan psikologi berjumlah 51\% dan nilai-nilai etika dan moral $41 \%$.
\end{abstract}

Kata kunci: tanggung jawab, obsesif, ambisi, cinta, dan taat.

\section{ABSTRACT}

In the mushrooming era of women's work in literature in 1970 with publication of magazines and tabloids, a few notable women became prominent writers. Nh. Dini was one of them. Dini's Fontenay de Magallihanse is worth studying again given the peculiarity of discussing morality and ethic as well as humanity. Her humanity is based upon the custom of the community, where ethical system and morality is produced. The study is employing qualitative method, analyzing moral and ethical issues of women. The finding of the study revealed that out of 22 scenes, $51 \%$ of them discussed values and psychology whereas the other $41 \%$ discussing ethical system.

Key words: works of women, obsession, ethical system, humanity

\section{Pendahuluan}

Sastra merupakan hasil cipta atau karya manusia yang dapat dituangkan melalui ekspresi yang berupa tulisan yang menggunakan bahasa sebagai mediumnya. Selain itu sastra juga merupakan hasil karya seseorang yang 
diekspresikan melalaui tulisan yang indah, sehingga karya yang dinikmati mempunyai nilai estetis dan dapat menarik para pembaca untuk menikmatinya.

Karya-karya yang indah ini dalam sastra berupa cerpen, puisi, novel dan drama. Dalam kajian ini penulis akan membedah sebuah novel. Seperti yang diungkapkan "The American College Dictonary (dalam Tarigan, 1986:120) bahwa novel adalah suatu cerita prosa yang fiktif dan panjang yang tertentu yang melukiskan para tokoh, gerak serta adegan kehidupan nyata yang representatif dalam suatu alur atau suatu keadaan yang agak kacau atau kusut. Sedangkan Abrams dalam Nurgiyanto, 1998:9. Karya novel biasanya mengangkat berbagai fenomena yang terjadi di masyarakat. Karya-karya yang menarik itu dapat mempengaruhi jiwa para pembaca sehingga dapat menyelami dan seolah-olah hadir dalam cerita tersebut.

Dalam penelitian ini, penulis sengaja mengambil novel Dari Fontenay ke Magallianes karya NH Dini karena tertarik terhadap karakteristik tokoh dan isi cerita yang terdapat di dalamnya. NH.Dini menyajikan kepada pembaca sebuah dunia kejiwaan manusia yang kelam, dan di dalam novelnya pula kita dapat bertemu dengan tokoh-tokoh yang berkecamuk dengan pikiran dan pandangan-pandangan hidupnya sendiri. Di novel ini tidak banyak diungkapkan tindakan-tindakan jasmani, akan tetapi, justru reaksi-reaksi kejiwaan yang lebih mewarnai kehidupan novel ini.

Dengan menggunakan metode kualitatif (Moleong 1988:3) dan kajian psikologi sastra (Frud, 2006:3) maka, kita berusaha memahami aspek kejiwaan serta sifat dan sikap para tokohnya dalam menjalani kehidupan yang terdapat dalam suatu cerita.

\section{Pembahasan dan Hasil}

Menurut asal katanya, psikologi berasal dari kata Yunani 'psyche' yang berarti jiwa dan ogos' yang berarti ilmu. Jadi, secara harfiah psikologi berarti ilmu jiwa. Namun pengertian jiwa tidak pernah ada kesepakatan dari sejak dahulu. Di antara pendapat para ahli, jiwa bisa berarti ide, karakter atau fungsi mengingat, persepsi akal atau kesadaran. Sementara, psikologi adalah ilmu yang sedang berkembang dan pada hakikatnya dapat diterapkan pada setiap bidang dan segi kehidupan. Oleh karena itu cabang-cabang psikologi bertambah dengan pesat, sejalan dengan perkembangan ilmu pengetahuan dan aktivitas kehidupan. Cabangcabang psikologi dapat digolongkan berdasarkan kekhususan bidang studinya, baik ilmu dasar (teoritis), maupun yang bersifat terapan (praktis). Penerapan psikologi berkembang ke berbagai aspek kehidupan manusia, demikian juga titik singgung dengan ilmu ilmu lain juga semakin banyak, misalnya dengan ilmu manajemen, ilmu ekonomi, ilmu perpustakaan, ilmu sosial dan sebagainya.

Berkait dengan yang di atas, psikologi adalah ilmu pengetahuan yang mempelajari perilaku manusia dan proses mental. Psikologi merupakan cabang ilmu yang masih muda atau remaja. Sebab, pada awalnya psikologi merupakan bagian dari ilmu filsafat tentang jiwa manusia. Mussen dan Rosenzwieg (dalam Effendi dan Praja, 1985: 63), menyatakan psikologi sebagai ilmu yang mempelajari tentang pikiran. Sejalan dengan perkembangan ilmu pengetahuan, kata pikiran berubah menjadi tingkah laku. Sehingga psikologi didefinisikan sebagai ilmu yang mempelajari tentang tingkah laku manusia. Menilik dari definisi tersebut, yang 
dipelajari dalam psikologi ialah tingkah laku manusia, melalui interaksi manusia dengan dunia sekitarnya, baik interaksi dengan manusia lain maupun yang bukan manusia; hewan, iklim, dan kebudayaan.Adapun menurut Walgito (2002: 8), psikologi adalah ilmu yang membicakan tentang jiwa. Namun, karena jiwa itu sendiri tidak menampak, maka yang dapat dilihat atau diobservasi ialah tingkah laku atau aktivitas-aktivitas yang lain. Karena itu psikologi merupakan suatu ilmu yang menyelidiki serta mempelajari tentang tingkah laku atau aktivitas-aktivitas, dan tingkah laku serta aktivitas-aktivitas itu sebagai manifestasi hidup kejiwaan.

Jiwa secara harfiah berasal dari perkataan sansekerta JIV yang berarti lembaga hidup (levensbeginsel), atau daya hidup (levenscracht). Oleh karena jiwa adalah merupakan pengertian yang abstrak, tidak bisa dilihat dan belum bisa diungkapkan secara lengkap dan jelas, maka, orang lebih cenderung mempelajari "jiwa yang memateri" atau gejala "jiwa yang meraga/menjasmani", yaitu bentuk tingkah laku manusia (segala aktivitas, perbuatan, penampilan diri) sepanjang hidupnya. Oleh karena itu, psikologi butuh berabad-abad lamanya untuk memisahkan diri dari ilmu filsafat.

Pada pokoknya, psikologi) serta pendekatan psikologi kepribadian McDouglall (1908) dalam Halll dan Lidzey (1993:23-24) berkelindan dengan masalah kegiatan psikis, seperti berpikir, belajar, menanggapi, mencinta, membenci dan lain-lain yang umumnya dibagi menjadi 4 kategori, yaitu:

1. Pengenalan atau kognisi,

2. Perasaan atau emosi,

3. Kemauan atau konasi,

4. Gejala campuran.

\section{A. Deskripsi Data}

Dalam penelitian ini, deskripsi aspek psikologi, moral dan etika berkaitan dengan pemaparan tentang sikap dan perilaku baik dan buruk yang ditampilkan tokoh utama dalam novel ini. Moral dan Etika yang ditampilkan terdiri atas pengaruh psikogis moral dan etika buruk; mengabaikan nilai-nilai budaya bangsa dan nilai-nilai kemanusiaan secara universal, sedang etika baik; dalam situasi dan kondisi tertentu terlihat dari berbagai interaksi, hubungan, dan proses sosial bahwa pada dasarnya tokoh dalam novel tersebut sebagai homo socius.

Sementara, deskripsi aspek psikologis berkaitan dengan tokoh wanita dan keadilan yang wujudnya tampak dalam berbagai perubahan tipikal tokoh dalam cara bersikap dan berperilaku sesuai dengan status sosial saat itu. Adapun, data penelitian ini disiapkan dalam bentuk tabel analisis aspek psikologi, moral dan etika yang selengkapnya disajikan dalam sub judul berikutnya.

\section{B. Sinopsis}

Berangkat dari sebuah novel yang berjudul Dari Fontenay ke Magallianes, karya Nh. Dini. Isi novel itu menjadi obyek materialistik yang diteliti, sedang obyek forma yang dicermati adalah unsur psikologi dan nilai-nilai moral dan etika yang ditampilkan oleh tokoh utama dalam novel tersebut. 


\section{Dari Fontenay ke Magallianes.}

Tidak ada yang bisa menepis, betapa novel yang satu ini mamu menggambarkan secara lugas tentang perspektif seorang perempuan dalam hidup dan kehidupannya, khususnya ketika ia sudah berumah tangga --- yakni sebagai istri, ibu dan sudah barang tentu sebagai seorang wanita.

Sebagai ibu, Dini memiliki dua orang anak, yakni Lintang dan Padang, sementara, sebagai istri, ia bersuamikan seorang diplomat Perancis, sedang sebagai wanita, ia juga merupakan sosok yang mempunyai cita-cita, keinginan dan haropan hidup yang lebih baik sebagaimana fitrahnya di samping kaum laki-laki.

Jika disimak dengan saksama, sebagai keluarga, maka, novel ini mampu untuk menjawabnya. Bahkan, ia juga tak memiliki masalah yang berarti dalam menjalankan perannya sebagai ibu dari dua orang anak. Namun sebagai istri, ia harus berhadapan dengan seorang suami yang egois. Agaknya, karena suami sebagai pencari nafah, maka, segala kehendaknya seolah menjadi hukum dan tak terbantahkan. Dan inilah yang membuat Dini mulai berontak!

Sebagai wanita yang normal, sudah barang tentu Dini juga mempunyai prinsip hidup, cita-cita dan harapan, keinginan dan lain sebagainya, namun apa daya, semua itu hanya tinggal impian. Manakala ia sudah mulai muak dengan ketertindasan yang melingkarinya, tak ada jalan lain, Dini pun mulai bersiap-siap untuk keluar.

Meski hal itu tak pernah dilakukan, namun, di sini sudah membuktikan akan nilai-nilai yang diyakininya. Apalagi, ketika hubungannya dengan sang kapten kapal yang bernama Bagus itu kian hari kian bertambah intim. Tanpa sadar, cinta terlarang pun berkelindan di antara keduanya. Betapa tidak, walau tidak sering, namun, di sela-sela waktu kosong ketika kapal sedang merapat ke dermaga, maka, mereka akan melewatkan waktu dengan berdua saja. Namun, dengan sekali bertemu dan berpisah untuk waktu yang lama mau tidak mau menyalurkan benih cintanya.

Di dalam novel ini, Dini tinggal di Fontenay, Perancis, di sebuah apartemen sederhana. Waktu itu, untuk pertama kalinya selama empat tahun i ia berhubungan badan yang menurutnya perkosaan dengan suaminya sendiri. Ia melakukannya bukan atas dasar cinta, walau begitu, lahirlah anak keduanya yang bernama Padang. Secara umum, novel ini banyak nilai-nilai moral --- mulai filosofi --- sebagai ibu sekaligus istri yang harus "sumarah dan sembadra" dalam menjalani pelbagai ragam kehidupan sehingga menimbulkan beberapa pertanyaan; Bagaimana posisi keduanya dalam ikatan perkawinan? Sucikah pernikahan mereka padahal diseling dengan perselingkuhan? Lalu, apakah perselingkuhan itu? Atau apakah novel ini merupakan kenyataan kehidupan wanita di saat ini?

\section{Deskripsi Temuan Penelitian}

Pada bagian ini penulis mengemukakan beberapa penemuan kalimat/adegan (scene) yang mencerminkan psikologis dan nilai-nilai moral, etika yang terkandung dalam novel ini. Kalimat-kalimat yang sarat akan unsur psikologis dan nilai-nilai moral, etika tersebut ditampilkan oleh sosok tokoh utama berikut: 
Deskripsi Temuan Penelitian

\begin{tabular}{|c|c|c|c|c|}
\hline No & Deskripsi Temuan & Hal & $\begin{array}{l}\text { Nilai-nilai/ } \\
\text { Psikologis }\end{array}$ & $\begin{array}{c}\text { Moral dan } \\
\text { Etika }\end{array}$ \\
\hline 1 & $\begin{array}{l}\text { "Alangkah benarnya semua itu! Dan } \\
\text { seumur hidupku, aku tidak pernah } \\
\text { melupakan nasihat ibuku" "Namun } \\
\text { kemudian, aku eling, kembali ke jalanku } \\
\text { serta menyerahkan segalanya kepada } \\
\text { Tuhan Yang Mahasa Kuasa. }\end{array}$ & 22 & & $\sqrt{ }$ \\
\hline 2 & $\begin{array}{l}\text { Menuruti ajaran orang tua, kuterima dan } \\
\text { kusyukuri apa pun Dia limpahkan } \\
\text { kepada ku. }\end{array}$ & 35 & & $\sqrt{ }$ \\
\hline 3 & $\begin{array}{l}\text { Semula aku sempat bingung ketika } \\
\text { mengetahui dia mulai hadir di dalam } \\
\text { diriku. Meneruskan hidup bersama lelaki } \\
\text { berwatak labil dengan siapa aku } \\
\text { memutuskan untuk hanya menjadi } \\
\text { :rekanan kongsi: atau associate cukup } \\
\text { mebikinku was-was. Kemudian kuketahi } \\
\text { bahwa aku mengandung! Meskipun } \\
\text { selama waktu-waktu akhir kurasakan } \\
\text { kembalinya sikap lembut dan perhatian } \\
\text { suami kepadaku, tetapi aku terlanjur } \\
\text { 'tidak terlalu mempercayai } \\
\text { "keberuntunganku dalam pilihan } \\
\text { pasangan hidup itu. Lebih-lebih } \\
\text { ketertarikan fisik atau kedekatanku } \\
\text { kepadanya sudah lenyap sama sekali. } \\
\text { Setiap kali bersentuhan dengan dia, } \\
\text { tubuhku bereaksi bertahan dan menolak" }\end{array}$ & 36 & $\sqrt{ }$ & \\
\hline 4 & $\begin{array}{l}\text { "dia membiarkanku seorang diri } \\
\text { mengurusi anak dan' pindahan kecil' } \\
\text { tersebut. Apalagi ia hanya menyewa } \\
\text { sebuah VW combi untuk mengangkut } \\
\text { barang-barang yang dikatakan hanya } \\
\text { sedikit itu, padahal alat-alat fotonya saja } \\
\text { sudah memenuhi dua pertiga kendaraan. }\end{array}$ & 38 & $\sqrt{ }$ & \\
\hline 5 & $\begin{array}{l}\text { Sekali lagi aku merasa dia hendak } \\
\text { menunjukkan: kekuasaannya: tidak mau } \\
\text { direpoti. Katanya, urusan rumah harus } \\
\text { kuselesaikan sendiri" }\end{array}$ & 39 & $\sqrt{ }$ & \\
\hline 6 & "Sungguh tidak ada gunanya berbantah & 50 & $\sqrt{ }$ & \\
\hline
\end{tabular}




\begin{tabular}{|c|c|c|c|c|}
\hline No & Deskripsi Temuan & Hal & $\begin{array}{l}\text { Nilai-nilai/ } \\
\text { Psikologis }\end{array}$ & $\begin{array}{c}\text { Moral dan } \\
\text { Etika }\end{array}$ \\
\hline & $\begin{array}{l}\text { dengan lelaki yang maunya menang } \\
\text { sendiri semacam dia. Terdorong oleh } \\
\text { rasa jahat dan usil di hati, nyaris aku } \\
\text { mengucapkan kata-kata yang kadang } \\
\text { mengungkit masalah yang sangat } \\
\text { pribadi. Untunglah aku segera eling. } \\
\text { Karena dengan lelaki seperti dia, tidak } \\
\text { ada diskusi wajar dan tenang. Yang ada } \\
\text { hanyalah 'debat kusir' berbantah atau } \\
\text { adu argumentasi. Maka aku terdiam dan } \\
\text { mengalah. Kata orang mengalah bukan } \\
\text { berarti benar-benar kalah, walaupun itu } \\
\text { hanya permainan kata. Dengan demikian } \\
\text { satu bongkahan besar lagi menambah } \\
\text { tekanan di dadaku" }\end{array}$ & & & \\
\hline 7 & $\begin{array}{l}\text { "Seperti kata ibuku, hidup ini terlalu } \\
\text { singkat, namun banyak keindahan dan } \\
\text { keistimewaan yang terkandung di } \\
\text { dalamnya" }\end{array}$ & 65 & & $\sqrt{ }$ \\
\hline 8 & $\begin{array}{l}\text { "Orang hidup bisa diumpamakan hanya } \\
\text { untk mampir, kata ibuku." Orang boleh } \\
\text { bersenang-senang atau bersedih karena } \\
\text { itu perasaan berguna, ciri khas kita } \\
\text { semua manusia" ditambah dengan } \\
\text { karunia akal dan budi, itulah yang } \\
\text { membikin manusia ingat atas ciptaan- } \\
\text { Nya." }\end{array}$ & 66 & & $\sqrt{ }$ \\
\hline 9 & $\begin{array}{l}\text { "sebab itu semampu kita harus tetap } \\
\text { eling, masing-masing dari kita } \\
\text { mempunyai tugas. Kita wajib } \\
\text { menjalankannya sambil terus berusaha } \\
\text { berbuat sebaik dan selurus mungkin } \\
\text { terhadap semua makhluk Yang Kuasa" }\end{array}$ & 66 & & $\sqrt{ }$ \\
\hline 10 & $\begin{array}{l}\text { "Sekarang kita bersama-sama, kita } \\
\text { nikmati saja apa yang kita miliki di saat } \\
\text { ini! Kata Ibuku. Jangan di isi hati kita } \\
\text { dengan kebencian atau makian. Itu } \\
\text { mengotori batin kita! }\end{array}$ & 76 & & $\sqrt{ }$ \\
\hline 11 & $\begin{array}{l}\text { "Kau benar! Ia pasti seorang wanita luar } \\
\text { biasa karena malahirkan dan mendidik } \\
\text { kamu sehingga menjadi dua , tiga, }\end{array}$ & 78 & & $\sqrt{ }$ \\
\hline
\end{tabular}




\begin{tabular}{|c|c|c|c|c|}
\hline No & Deskripsi Temuan & Hal & $\begin{array}{l}\text { Nilai-nilai/ } \\
\text { Psikologis }\end{array}$ & $\begin{array}{c}\text { Moral dan } \\
\text { Etika }\end{array}$ \\
\hline & $\begin{array}{l}\text { empat, sampai entah berapa kelipatan } \\
\text { luar biasa dari dirinya" }\end{array}$ & & & \\
\hline 12 & $\begin{array}{l}\text { "Mengapa tidur } \\
\text { dikatakan'bercinta' jikaperbuatan itu } \\
\text { tidak disadari rasa saling mencinta. } \\
\text { Setitik rasa kelembutan telah lenyap dari } \\
\text { pihakku dari lelaki pilihan yang kunikahi } \\
\text { dulu. Berdekatan dengan dirinya tidak } \\
\text { lagi memberiku suatu rangsangan } \\
\text { apapun. Aku bahkan muak bila ia } \\
\text { menyentuhkan bibirnya ke mulutku" }\end{array}$ & 98 & $\sqrt{ }$ & \\
\hline 13 & $\begin{array}{l}\text { "Empat tahun tanpa persetubuhan } \\
\text { dengannya.Satu kali itu dilakukannya } \\
\text { bersamaku, janganlah itu Kaubikin } \\
\text { berhasil membuahi rahimku! Kumohon } \\
\text { aku diselamatkan dari semua kerepotan } \\
\text { yang disebabkan oleh perbuatan kami } \\
\text { berdua malam itu" }\end{array}$ & 99 & $\sqrt{ }$ & \\
\hline 14 & $\begin{array}{l}\text { "Penyesalan yang berkecamuk } \\
\text { dikepalaku itu menggangu konsentrasi } \\
\text { doa-doaku. Aku mohon perlindungann- } \\
\text { Nya. Aku minta ampun karena } \\
\text { mengingkari lelaki ayah anakku. Tanpa } \\
\text { kukehendaki, mataku penuh air, } \\
\text { kubiarkan turun deras membasahi kedua } \\
\text { pipiku }\end{array}$ & 100 & $\sqrt{ }$ & \\
\hline 15 & $\begin{array}{l}\text { "Sudah sejak kami masih hidup di negeri } \\
\text { Belanda, Lintang kuberitahu mengenai } \\
\text { kandunganku. Anak seusianya pasti } \\
\text { sudah mendengar cerita-cerita yang } \\
\text { beredar di antara teman-teman sekolah } \\
\text { sebayanya tentang dari mana asal } \\
\text { seorang bayi. Oleh karena itu kukatakan } \\
\text { yang sebenarnya tentang hubungan } \\
\text { pasangan tanpa melewati batas-batas } \\
\text { pengertian sesederhana mungkin. }\end{array}$ & 176 & $\sqrt{ }$ & \\
\hline 16 & $\begin{array}{l}\text { Jika dua manusia atau binatang saling } \\
\text { tertarik, lebih-lebih saling mencintai, } \\
\text { mereka berkasih-kasihan, lalu pihak } \\
\text { jantan memasukan benih calon jenisnya } \\
\text { kedalam perut si betina. Seperti tanaman }\end{array}$ & 177 & $\sqrt{ }$ & \\
\hline
\end{tabular}




\begin{tabular}{|c|c|c|c|c|}
\hline No & Deskripsi Temuan & Hal & $\begin{array}{l}\text { Nilai-nilai/ } \\
\text { Psikologis }\end{array}$ & $\begin{array}{c}\text { Moral dan } \\
\text { Etika }\end{array}$ \\
\hline & $\begin{array}{l}\text { benih itu tumbuh dan dijadikan Tuhan } \\
\text { replika atau copy kedua orang tuanya. } \\
\text { Lintang tampak menerima penjelasanku } \\
\text { dengan baik. Pada waktu-waktu tertentu, } \\
\text { ia kusuruh menyentuh perutku yang } \\
\text { membun-cit.Kuajari dia mencari denyut } \\
\text { jantung si janin"” }\end{array}$ & & & \\
\hline 17 & $\begin{array}{l}\text { Pertemuanku dengan Bagus sangat } \\
\text { lancar.Selama tiga hari, aku merasa } \\
\text { seolah-olah beban yang menekan dan } \\
\text { menghimpit dada serta pundakku } \\
\text { dilepaskan orang. Seakan-akan akau } \\
\text { diberi libur. Dibebaskan dari } \\
\text { kungkungan ruang sempit yang } \\
\text { menyasakkan" }\end{array}$ & 202 & $\sqrt{ }$ & \\
\hline 18 & $\begin{array}{l}\text { Selain mendapatkan perhatian penuh } \\
\text { dalam percakapan ringan disertai kelakar } \\
\text { canda. Diskusi serius yang lembut, } \\
\text { namun terus terang'pelayanan'biologis } \\
\text { yang luar biasa pun kudapatkan tanpa } \\
\text { hitungan. }\end{array}$ & 202 & $\sqrt{ }$ & \\
\hline 19 & $\begin{array}{l}\text { Bersama Bagua akau menemukan } \\
\text { kembali kenikmanatan menjadi pasangan } \\
\text { sorang manusia lelaki. Bagiku itulah } \\
\text { yang benar-benar yang dinakana Faire } \\
\text { I'amour (bercinta). Bukan hanya sekadar } \\
\text { bersetubuh, melaikan melakukan } \\
\text { tindakan apa yang disebut orang jawa } \\
\text { lambangsari,ialah memadu kasih dengan } \\
\text { cara mepertemukan sari atau inti kedua } \\
\text { makhluk yang saling mencintai, } \\
\text { kalaupun tidak saling mempedulikan } \\
\text { kebutuhan jasmani pasangan masing- } \\
\text { masing. }\end{array}$ & 203 & $\sqrt{ }$ & \\
\hline 20 & $\begin{array}{l}\text { "Pelajaran sekolah semakin meningkat } \\
\text { dan anak sulungku semakin mandiri. } \\
\text { Dulu aku selalu mendampinginya ketika } \\
\text { mengerjakan PR. Kemudian, ia } \\
\text { berangsur-angsur ia dapat menyelesaikan } \\
\text { tugas-tugasnya tanpa campurtanganku. } \\
\text { Kecuali dalam beberapa hal. Biasanya }\end{array}$ & 230 & & $\sqrt{ }$ \\
\hline
\end{tabular}




\begin{tabular}{|c|c|c|c|c|}
\hline No & Deskripsi Temuan & Hal & $\begin{array}{l}\text { Nilai-nilai/ } \\
\text { Psikologis }\end{array}$ & $\begin{array}{l}\text { Moral dan } \\
\text { Etika }\end{array}$ \\
\hline & $\begin{array}{l}\text { sewaktu ada tugas menyusun tulisan } \\
\text { mengenai sesuatu mata pelajaran, } \\
\text { misalnya membuat sinopsis buku wajib, } \\
\text { karena anak-anak setingkatnya sudah } \\
\text { diminta untuk membaca buku-buku } \\
\text { karangan para penulis terkenal. Dalam } \\
\text { mata pelajaran sejarahpun, siswa } \\
\text { diwajibkan membuat karangan singkat } \\
\text { yang berhubungan dengan tokoh-tokoh } \\
\text { nasional atau internasional. Juga dalam } \\
\text { pelajaran desain. Lintang tidak jarang } \\
\text { meminta pendapatku. Dalam hal } \\
\text { demikian aku tahu diri berhati-hati dalam } \\
\text { membimbing, karena kujaga agar ia tidak } \\
\text { mengira aku sombong, yang paling } \\
\text { mahir, serta sok tahu. }\end{array}$ & & & \\
\hline 21 & $\begin{array}{l}\text { "pengasuh dan anak semangku } \\
\text { kuarahkan untuk mengikuti alur } \\
\text { keseharian Padang. Di antaranya } \\
\text { Dominique harus makan seperti orang- } \\
\text { orang besar, artinya duduk di meja } \\
\text { makan, lengkap dari suguhan utama } \\
\text { sampai ke pencuci mulut. Bahkan } \\
\text { handuk kecil yang basah, sekurang- } \\
\text { kurangnnya agar anggota badannya } \\
\text { bersih serta segar jika tangan anak-anak } \\
\text { memang harus dicuci. Tidak jarang } \\
\text { mukanya di-lap dengan handuk kecil } \\
\text { yang basah, sekurang-kurangnya agar } \\
\text { anggota badan tersebut bersih serta } \\
\text { segar seusai makan jika hendak langsung } \\
\text { beristirahat di ranjang masing-masing. } \\
\text { Aku juga banyak berdialog dengan anak. } \\
\text { Kuajak mereka membiasakan diri dalam } \\
\text { cara hidup kami sehari-hari. Aku bukan } \\
\text { seorang ibu yang kejam, namun anak- } \\
\text { anaku kuajari hidup berdisiplin dalam } \\
\text { kesantunan" }\end{array}$ & 289 & & $\sqrt{ }$ \\
\hline 22 & $\begin{array}{l}\text { "Katanya terima kasih, terima kasih! } \\
\text { Apakah tuan konsul sudah mengatakan } \\
\text { bahwa kami mengaumi teknik mendidik } \\
\text { Anda? Belum? Wah, Dominique }\end{array}$ & 292 & & $\sqrt{ }$ \\
\hline
\end{tabular}




\begin{tabular}{|l|l|l|l|l|}
\hline No & \multicolumn{1}{|c|}{ Deskripsi Temuan } & Hal & $\begin{array}{c}\text { Nilai-nilai/ } \\
\text { Psikologis }\end{array}$ & $\begin{array}{c}\text { Moral dan } \\
\text { Etika }\end{array}$ \\
\hline & $\begin{array}{l}\text { sekarang sudah menjadi bocah laki-laki } \\
\text { yang hampir sempurna. Ia bisa dengan } \\
\text { tenang makan di meja, tidur siang } \\
\text { dengan teratur. Dan yang paling baik } \\
\text { ialah ia tidak berteriak-teriak lagi. Apa } \\
\text { yang dapat kami berikan kepada Anda } \\
\text { sebagai ganti jasa baik itu? Apa yang } \\
\text { dapat mebuat hati Anda senang? }\end{array}$ & & \\
\hline
\end{tabular}

Deskripsi temuan di atas, penulis guguskan sebagai berikut :

\begin{tabular}{|c|l|c|c|}
\hline No & \multicolumn{1}{|c|}{ Hasil temuan deskrpsi } & Jumlah temuan & Persentase \\
\hline 1 & Nilai-nilai kejiwaan psikologis & 13 & $59 \%$ \\
2 & Nilai-niali Moral dan etika & 9 & $41 \%$ \\
\hline & Jumlah temuan & 22 & $100 \%$ \\
\hline
\end{tabular}

Berdasarkan deskripsi data di atas, maka, dapat diketahui bahwa alur cerita dalam novel tersebut sarat akan unsur kejiwaan/psikologi dan nilai-nilai psikologis, moral dan etika yang implementasinya terlihat pada sikap dan perilaku; tanggung jawab, obsesif, ambisi, cinta, dan taat. Selanjutnya berdasarkan analisis data dan informasi di atas, diketahui bahwa dari jumlah 22 temuan/adegan cerita (scene), ternyata adegan-adegan yang menunjukkan nilai-nilai kejiwaan/psikologis berjumlah $59 \%$ moral dan etika $41 \%$.

Dengan memperhatikan isi (content) novel tersebut, secara umum dapat dikatakan bahwa novel itu sarat akan unsur kejiwaan/psikologis, moral dan etika, pendidikan, moral, ideologi, filsafat, dan psikologi yang dikemas dengan bahasa lugas. Unsur kejiwaan dan nilai-nilai yang terkandung dalam novel tersebut ditampilkan oleh tokoh utamanya yaitu Dini, seorang perempuan jawa yang taat.

Ada beberapa nilai yang diperankan oleh tokoh Dini berkaitan dengan unsur psikologis, moral dan etika. Di samping nilai-nila tersebut di atas, tampak pula dalam dimensi-dimensi lain, di antaranya: obsesi, ambisi, cinta, Nilai-nilai tersebut ada yang bersifat positif, dan ada yang bersifat negatif. Nilai-nilai yang bersifat positif antara lain : tidak pernah merasa puas terhadap apa yang telah dicapai, tetap ingat atas nasihat ibunya, sangat menginginkan kembali ke suami pertamanya.

\section{Penyajian Pola psikologis}

Sebagai pengarang tentu menghendaki agar hasil karyanya benar-benar dapat dinikmati oleh para pembaca sehingga mereka larut dalam sistem dan alur cerita dalam bacaan itu. Dengan demikian, para pembaca seolah-olah menjadi bagian dari keseluruhan cerita. Oleh karena itu, teknik penyajian cerita dan 
penggunaan bahasa oleh setiap pengarang menjadi instrumen dan media penghubung pola pikir serta pesan-pesan pengarang kepada para pembacanya, sehingga, pembaca turut larut dalam suasana (kondisi) yang ditampilkan dalam cerita.

Seperti telah diutarakan, novel ini adalah novel biasa tentang obsesi, ambisi, harta dan cinta --- dengan kata lain, tema yang diusung oleh pengarang novel ini adalah psikologi, moral dan etika yang ditampilkan oleh seorang perempuan bemama Dini yang memiliki karakter pragmatis, ambisius, taat, dan simplisis.

Kemudian, alur cerita ditulis secara runtut (sistematik) yang dimulai dengan menampilkan kehadiran seorang perempuan yang taat dan menjadi istri seorang diplomat di Perancis, yang hendak meraih kesuksesan-kesuksesannya dalam mewujudkan setiap mimpi, cita, dan kehendak dirinya.

Sekalipun dalam kehidupan pribadinya ia sering mengabaikan cinta dan sisi kewanitaanya; "Aku adalah seorang perempuan yang ditakdirkan Tuhan seperti perempuan kebanyakan yaitu harus menyerahkan diri kepada Tuhannya", namun, karena perbedaan karakter antara ia dengan suaminya dalam prinsip, cara pandang, dan seterusnya, maka, pernikahan tersebut tidak harmonis dan harus berujung walau tanpa ada perceraian. Pola, alur, dan perwatakan yang ditampilkan oleh tokoh utama novel ini menjadi keharmonisan tema yang hendak disampaikan oleh pengarangnya mongenai pengaruh batin secara psikologisi oleh obsesi, ambisi, dan cinta.

\section{E. Penafsiran dan Uraian}

Sebelum penulis tafsirkan beberapa hasil temuan sebagaimana diuraikan pada bagian sebelumnya, pada bagian ini penulis akan mendeskripsikan sinopsis dari keseluruhan isi yang terdapat dalam novel Dari Pontenay ke Magallianes dengan harapan dapat memberikan ilustrasi kepada penulis dalam memberikan penafsiran tersebut.

Novel ini mengisahkan tentang kejiwaan, obsesi, ambisi, dan cinta dalam bahasa sederhana dan mengesankan. Sebuah novel yang kaya akan muatan filsafat serta menarik untuk diikuti.

Adapun, pesan yang diinginkan oleh pengarang novel ini adalah bahwa pengaruh kejiwaan/psikologis, moral dan etika harus segera mendapat pengakuan dari semua orang.. Meskipun demikian, ada beberapa nilai yang dapat dipetik sehubungan dengan pengaruh kejiwaan/psikologis yang ditumbuhkembangkan dalam setiap ruang dan waktu karena kebenarannya memiliki nilai-nilai universal, di antaranya aktivis. Sebagaimana kita ketahui, aktivitas merupakan kausalitas dari obsesi dan ambisi seseorang dan faktor tantangan (kesempatan, kans) lingkungan yang mendorong (menstimulan) seseorang untuk beraktivitas seperti yang dilakukan seorang tokoh Dini.

\section{F. Simpulan}

Berdasarkan hasil analisis latar, alur, ketokohan, dan tema dalam novel Dari Fontenay ke Magallianes karya Nh, maka, tampak dengan jelas betapa nilai-nilai kejiwaan psikologi yang paling banyak ditemukan dalam isi cerita --- di sini tokoh 
utama yang bernama Dini adalah sosok yang memiliki karakter kuat. Ia seorang perempuan istri diplomat yang taat, namun memberontak, tidak bertanggung jawab, obsesif, ambisi, cinta. Maka, tidak heran bila ia selingkuh dengan Bagus dan orangorang kebanyakan yang mengenal dirinya. Selanjutnya, berdasarkan analisis data dan informasi di atas diketahui bahwa dari jumlah 22 temuan/ adegan cerita (scene) yang menunjukkan adegan nilai-nilai/ kejiwaan psikologi berjumlah $51 \%$ dan nilainilai etika dan moral $41 \%$.

Selanjutnya, kecenderungan nilai kejiwaan yang dominan adalah pragmatisme, tidak bertanggung jawab, obsesif, ambisi, cinta, memberontak, selingkuh. Namun ia tetap mempertahankan rumahtangganya. Di sini pengarang bermaksud, bahwa dengan submisifnya nilai kebersalahan dan moral serta etika, ia mengajak para pembaca dan masyarakat luas untuk meningkatkan perenungan tentang hidup. Ternyata hidup adalah perjalanan impian menuju kematian.

Selaras dengan yang tersebut di atas, sejatinya, nilai yang diperankan oleh Dini berkaitan dengan kejiwaan, moral dan etika. Di samping nilai-nila tersebut, tampak pula dimensi-dimensi lain di antaranya: obsesi, ambisi, cinta, dan selingkuh --- sudah barang tentu, nilai-nilai tersebut ada yang bersifat positif, dan ada yang bersifat negative --- yang bersifat positif antara lain: tidak pernah merasa lelah terhadap apa yang telah dicapai, mendidik kedua anaknya, dan mandiri, mempertahankan keluarga; sedangkan sisi negatif dari seorang Dini adalah : kesepian, gila kehormatan (ambisius), mendewakan harga, berselingkuh.

\section{Daftar Pustaka}

Aminuddin 1987. Pengantar Apresiasi Karya Sastra. Bandung: Sinar Baru Algesindo.

Arikunto, Suharsimi. 1998. Prosedur Penelitian Suatu Pendekatan Praktek. Jakarta : Rineka Cipta.

Adjl Z. Januar, 1997, Teori Sastra, Jakarta : Direktorat Jenderal Pendidikan Dasar dan Menengah.

Aryatirtawirya, 1993, Apresiasi Sastra dan Prosa, Ende-Ftores : Nusa Indah

Baker, 1979, Konsep Seni Sastra - Cerpen dan Novel, Kualalumpur : Dewan Bahasa dan Pustaka.

Badudu, Yus, 1996, Sari Kesusastraan Indonesia, Bandung : Pustaka Prima Driyarkara, 1996, Percikan Filsafat, Jakarta : Gramedia.

Driyarkara. 2008. Filsafat : Sebuah Pengantar. Jakarta : Gramedia.

Departemen Pendidikan Nasional.2003.Kurikulum 2004.Jakarta. 
Echol, F. John, dan Hasan Shadily, 1996, Kamus Inggris Indonesia, Jakarta : Gramedia.

Esten, Musal, 1978, Kesusastraan : Pengantar Teori dan Sejarah, Bandung : Angkasa.

Hanum, Zulfa, 2004, Metode Penelitian Kesusastraan, Selangor : Darul Ehsan. ,2005, Psikologi Kesusastraan, Depok : Inti Prima Grafhic.

Hatta, Muhammad. 2006. Alam Pikiran Yunani. Jakarta : Gramedia.

Hornby, 1996, The Progressive English Dictionary, London : Oxford University Press.

Hudson, W.H., 1997, An Introduction to The Study of Literature, London : George G. Harrap \& Co.

Jaya. Universitas Indraprasta PGRJ, 2004, Pedoman Penyusunan Skripsi, Jakarta: Tanpa Penerbit.

Jassin, H.B., 1985, Penyair dan Daerahnya, Jakarta: Gunung Agung.

Kamus Umum Bahasa Indonesia, 1996, Jakarta : Pustaka Sinar Harapan.

Kamus Umum Lengkap Internasional Populer, 1978, Jakarta : Series 555.

Kledon, Ignas, 2008, Sejarah Filsafat, Yogyakarta : Kanisius.

Kartono, Kartini. 1996. Psikologi Umum. Bandung: Mandar Maju

Luxemburg, Jan Van, 1996, Pengantar Ilmu Sastra : Tejemahan Dick Handoko, Yogyakarta: Kanisius.

Moleong, Lexy J. 1989. Metodologi Penelitian Kualitatif. Bandung: Remadja Karya.

Magnis Suseno, 1996, Filsafat Manusia, Jakarta : Gramedia

Nurgiyarttoro, Burhan, 1995, Bimbingan Apresiasi Sastra. Ende-Flores : Nusa Indah. . Teori Pengkajian Fiksi, Yogyakarta : Gajah Mada University Press.

Nurgiyantoro, Burhan. 2000. Teori Pengkajian Fiksi. Yogyakarta: Gajah Mada University Press. 
Rahmanto. B. 1988. Metode Pengajaran Bahasa. Yogyakarta: Kanisius

Ratna, Nyoman Kutha. 2009. Teori, Metode, dan Teknik Penelitian Sastra. Yogyakarta: Pustaka Pelajar.

Rahmanto, B., 1998, Pengamar Apresiasi Sastra, Malang : Lembaga Penerbitan Universitas Brawijaya.

Reene, Wellek, 1990, Theory of Literature, New York : Harveas Book Harcourt HW. Inc.

Saad, Saleh, 1976, Tentang Kritik Sastra, Jakarta : Gunung Agung.

Semi, Atar, 1993, Anatomi Sastra, Padang : Angkasa Raya.

Semi, Atar. 1990. Metode Penelitian Sastra. Padang : Angkasa.

Suroto. 1989. Teori dan Bimbingan Apresiasi Sastra Indonesia. Jakarta: Erlangga

Syah, Muhibbin. 2000. Psikologi Pendidikan dengan Pendekatan Baru. Bandung: Remaja Rosdakarya.

Sukarto, Sugihastuti, 2002, Kritik Sastra, Jakarta : Pusat Pembinaan Pengembangan Bahasa.

Sumardjo, Jakob, 1998, Aprtssiasi Kesusastraan, Bandung : Angkasa

Tarigan, Hendry Guntur. 1986, Prinsip-Prinsip Dasar Sastra, Bandung : Angkasa.

Teeuw A., 1983, Sastra dan Ilmu Sastra; Pengatur Teori Sastra, Jakarta : Pustaka

Warren, Austin, 1989, Kesusastraan : Pengantar Teori dan Sejarah, Bandung : Angkasa.

Yassin, H.B., 1986, Tifa Penyair dan Daerahnya, Jakarta : Gunung Agung

Zulfahnur, Z.F., 1997, Teori Sastra, Jakarta : Direktorat Jenderal Pendidikan Dasar dan Menengah Depdikbud.

Zain, Moh Sutan. Dan J.S. Badudu. 2000. Kamus Umum Bahasa Indonesia, Jakarta; Pustaka Sinar Harapan.

Wirawan, Sarwono Sarlito. 2000. Pengantar Umum Psikologi. Jakarta: Bulan Bintang. 